\title{
Giant ovarian cyst in a woman in rural Africa
}

\author{
Babak Kianifard • James English • Geraldine Leger
}

Received: 7 June 2007 / Accepted: 5 July 2007 /Published online: 15 August 2007

(C) Springer-Verlag 2007

\begin{abstract}
A 42-year-old woman presented to the open access surgical outpatients clinic run by an international Non-Governmental Organisation in the south western region of Chad in central Africa. She gave a 2-year history of increasing abdominal girth, which had recently been associated with breathlessness and lower back pain. This had forced her to stop work, culminating in her self-referral to the clinic. In the absence of access to helpful investigatory modality, we performed an exploratory laparotomy, during which a large cyst $(15.1 \mathrm{~kg}, 12.5 \mathrm{l})$ in the left ovary was excised and abdominoplasty was performed. She made a good recovery with no complications and was discharged 5 days postoperatively.
\end{abstract}

Keywords Ovarian cyst · Laparotomy · Laparoscopy

\section{Introduction}

Modern treatment of giant ovarian cysts involves blood tests, such as those for tumour markers (e.g. CA 125), and imaging before surgical excision. The intervention can be performed laparoscopically after drainage of the cyst either pre-operatively under imaging guidance [1] or per-

\footnotetext{
B. Kianifard $(\bowtie) \cdot$ J. English

Worthing Hospital,

Lyndhurst Road,

Worthing, West Sussex BN11 2DH, UK

e-mail: bkianifard@hotmail.com

G. Leger

Clinic St. Catherine,

St. Catherine Les Arras, France
}

operatively via the laparoscope port [2], supra-pubic catheter [3] or a mini-laparotomy [4]. This case report presents the management and findings of a giant ovarian cyst in a woman in rural Africa, in an environment with limited access to haematological and imaging investigations.

\section{Case report}

A 42-year-old multiparous woman presented herself to the open access surgical outpatients clinic in the south western region of Chad. Via a translator, it became apparent that she had noted a gradual swelling of her abdomen over the preceding 2 years. She had originally felt that this might have been a pregnancy; however, her menstrual cycle had continued normally and she had failed to recognise all other systemic changes that she had noted in her previous pregnancies. As she had no other symptoms that would have stopped her work as a farmer and housewife, she had ignored the swelling. She had continued her work in the field (crop farming), but recently had found this increasingly difficult due to shortness of breath and lower back pain. She was otherwise fit and well and had no previous medical history of note.

Physical examination revealed her to be a slight woman with a markedly enlarged and protruding abdomen (Fig. 1). Her vital signs were all within normal limits. Abdominal examination revealed a non-tender, circumferentially distended abdomen with no fluid thrills or shifting dullness. It was not possible to palpate and distinguish any abdominal viscera on palpation and percussion. Digital rectal examination gave normal findings, and vaginal examination revealed a normal vagina with an impalpable uterus per abdomen. 


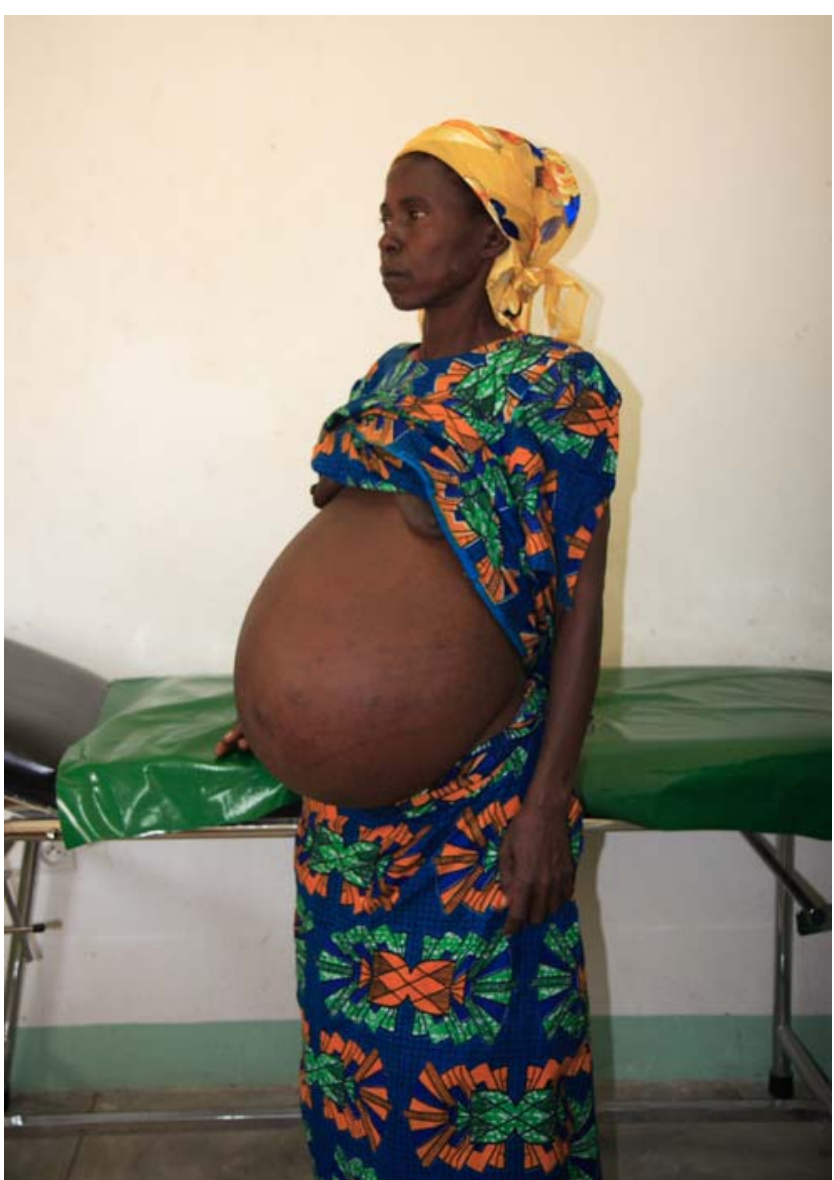

Fig. 1 The patient, with a large intra-abdominal mass

In view of these findings a presumptive diagnosis of giant ovarian cyst was made, but, in the environment in which she presented, a definitive pre-operative diagnosis was not possible. There was no easy access to any form of radiological imaging, and the haematological investigations available consisted of full blood cell count, which was within normal limits. As she was significantly limited in her daily undertakings by this pathological condition, it was decided to proceed to an explorative laparotomy.

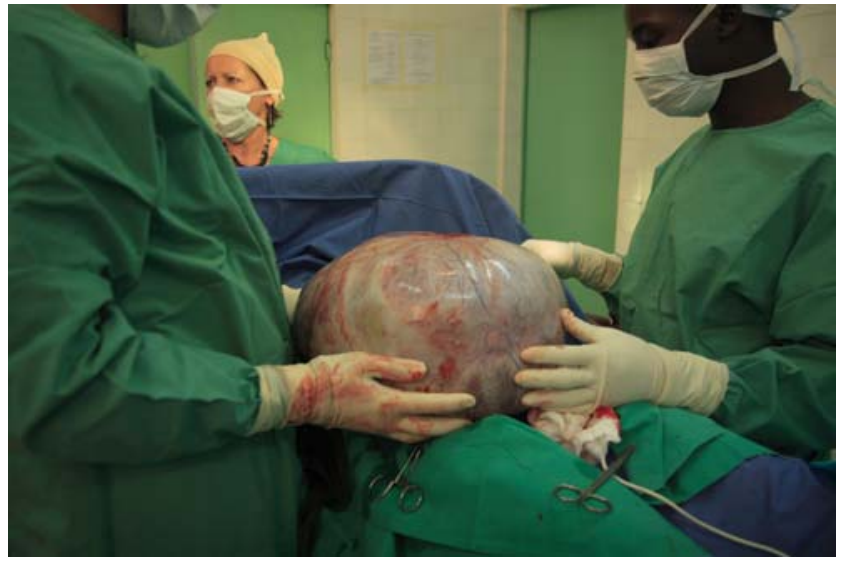

Fig. 2 Salpingo-oophrectomy performed at exploratory laparotomy

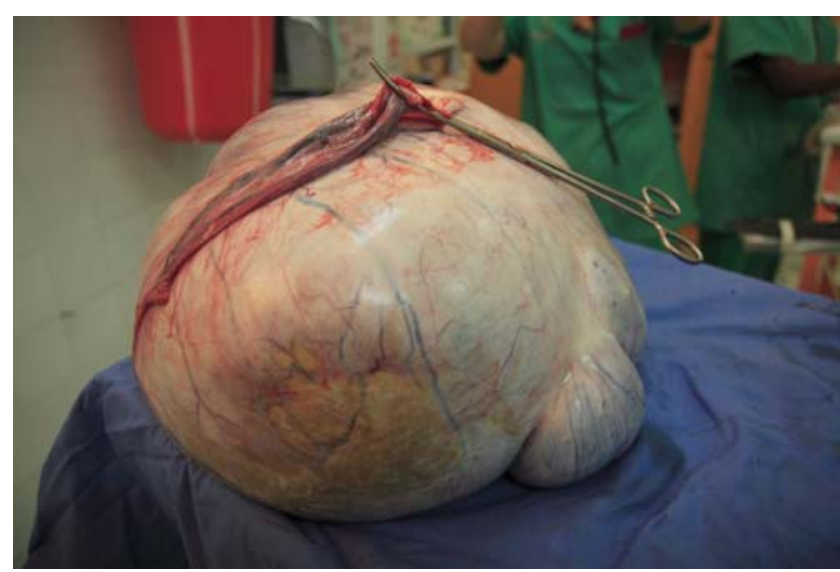

Fig. 3 Giant ovarian cyst excised at laparotomy

At laparotomy, a large cystic mass, arising from the left adnex, was found, which was smooth and non-adherent and occupied the entire abdominal cavity (Fig. 2). There was no evidence of ascites within the abdominal cavity. A left salpingo-oophrectomy (Fig. 3) was performed, together with an extensive abdominoplasty, with a large length of redundant skin and fat excised (Fig. 4). The removal of the cyst was not associated with any immediate adverse cardiovascular changes, and the patient remained stable throughout the procedure. The specimen was opened and was found to contain 12.51 of fluid and was devoid of any septae. As there was no access to pathological and histological investigations, the specimen was discarded, but, macroscopically, it resembled a cystadenoma. The patient made an uneventful recovery and was discharged back to her village on the fifth post-operative day.

\section{Discussion}

Within the realms of modern medicine, giant ovarian cyst are rare, as they are normally diagnosed and treated relatively early in their development. However, when

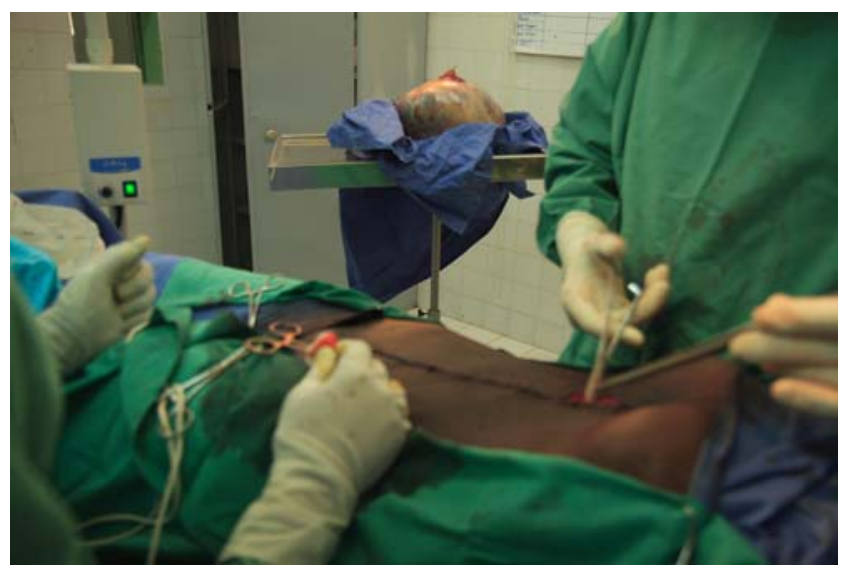

Fig. 4 Closure of abdomen after abdominoplasty 
present, they are investigated by imaging and tumour markers (CA 125) and can then be excised laparoscopically after drainage of the cyst [1-5].

In the third world, where survival is often determined by access to food and presence of politically mediated violence, the patients tend to ignore asymptomatic pathological conditions such as those described here until there is an impact on essential daily chores pertinent to survival. In this case, laparotomy also afforded the added luxury of an extensive abdominoplasty, which is not performed as part of a laparoscopic procedure.

Although some believe modern medicine to be overdependant on modern techniques and imaging investigations, in the absence of such tests definitive diagnosis is possible only by an exploratory laparotomy, perhaps better classed as an investigation with therapeutic possibility, in settings such as described here.

\section{References}

1. Nagele F, Magos A (1996) Combined ultrasonographically guided drainage and laparoscopic drainage of a large ovarian cyst. Am J Obstet Gynaecol 175:1377-1378

2. Eltabbakh GH, Kaiser JR (2000) Laparoscopic management of a large ovarian cyst in an adolescent. A case report. J Reprod Med 45:231-234

3. Dolan MS, Boulanger SC, Salameh JR (2006) Laparoscopic management of giant ovarian cyst. JSLS 10:254-256

4. Postma VA, Wegdam JA, Janssen IM (2002) Laparoscopic extirpation of a giant ovarian cyst. Surg Endosc 16:361

5. Salem HA (2002) Laparoscopic excision of large ovarian cyst. J Obst Gynaecol Res 28:290-294 